\section{The Development of an Autonomous Social Science Tradition in Asia: Problems and Prospects}

Syed Hussein ALATAS

Institute of Malay World Civilizations

National University of Malaya

Since my student days at the University of Amsterdam, in the early fifties, I have been intuitively concerned with the need for an autonomous social science tradition in the various regions of the world. During that period, on reading Ibn Khaldun, I was told that art could not develop without artists. By the same token, an autonomous tradition cannot develop without the commitment of an intellectual, creative and independent group striving for that tradition.

I then raised the question: what were the factors conducive to the birth of such a tradition and what were the serious impediments? In order to liberate, one must first understand the condition of bondage. This led me to the problem of the captive mind.

During the 11 th World Conference of the Society for International Development New Delhi, 14-17 November 1969, I presented a paper entitled "The Captive Mind in Development Studies". I commented on the intense bombardment on the developing societies of an ever-growing volume of literature from the West resulting in uncritical assimilation by the scholars developing societies, which did not have a functioning group of independent scholars leaving aside isolated individuals who could react critically and selectively.

A critical and selective reaction does not involve only those contriAutions that are given attention, but also those that are ignored. Ignoring a valuable contribution from the West is as negative as uncritically accepting whatever is served on the academic platter. The dish is relished with the ingredients are Like the out concern for how it is cooked and what the ingredients are. Like the
side effects of fast food, many of such imported intellectual recipes advertently affect the consumers.

Coming back to our theme, during the last few decades suggestions have been made that an Asian social science tradition be generated. A is ill an idea not yet dominant amongst Asian socia scientists. What I mean by an autonomous Asian social science tradition should not be confused with the often repeated suggestion that we pay attention to local problems with appropriate methodology. That is also a genuine concern as very often attention towards local problems is pursued in an alien manner. But this is different from the idea of an autonomous tradition.

Let us now inquire what an autonomous Asian social science tradition means. It is the linking of social science research and thinking to specifically Asian problems. Is there a justification for such a goal? There already exists an idea of an American or European social science tradition. Though both draw upon a common universal fountain of social science knowledge, yet we do speak of an American or European social science tradition. On further reflection it is discovered that the formation of a particular tradition is based on the following factors: (1) The raising and treatment of definite problems, (2) the application of definite methodologies, (3) the recognition of definite phenomena, (4) the creation of definite concepts, and (5) the relation with other branches of knowledge.

It is the special features around the above factors peculiar to a social science tradition that distinguish it from other traditions. The precise wideranging nature of this tradition would include certain distinctive variations. What I should like to discuss here is certain problems pertaining to the development of an autonomous tradition in Asia, either by individual countries or the region as a whole.

The domination of the greater part of mankind by Western civilisation has led to certain positive as well as negative effects. Our concern in the field of the social sciences is to identify these two effects and to avoid the negative ones. There are many negative effects, but I shall concentrate here on the conception of social science that prevails amongst an influential segment of the Asian social science community.

Let me illustrate with an example. Several years ago, at the National University of Singapore I read out in class an article on education written by a sociologist. The entire class thought that this was the situation of education in Singapore. But this was not so. This article was about another Asian country. I merely substituted the name "Singapore" in place of the country's original name. The strange thing was that it clicked. There was nothing wrong with the content. It dealt with a general concept and processes, and attempted causal analyses of the kind that are valid everywhere. When I told the students that the article was not about Singapore, they were truly shocked.

Clearly there is something wrong with such scholarship. The author an Asian sociologist, had picked up the habit of discourse, employing a stock of general concepts and method of analysis, citing here and there certain facts from his country, but clearly not focusing on the distinctive features of this society. This is nothing but imitation of instant scholarship that abounds in the fields of economics, political science, sociology and development studies. Scholars in these areas are sometimes in a hurry or have limited access to the empirical data; this tempts them to become mere 
imitators. They are not familiar with the historical and cultural background of their own societies. They rely mainly on published documents and monographs written by Westerners. As such, they are not able to go beyond general statements or presentation of quantitative data. Their studies remain superficial; they do not succeed to unravel the deeper problems of Asian societies.

Although there are studies that are sufficiently factually oriented towards the country, but again they fail to identify significant problems pertaining to the country or region. If it is an economic study of the Philippines, it resembles many economic studies of the United States with the only difference that the facts are from the Philippines - the same method, the same concepts and the same kind of problems. I am not saying that entire Asian social science literature is of this kind. There are some good studies too, but the overriding trend is of the imitative type. In my other publications, which are being developed into a book. I have given ample examples of this trend. But I will not repeat them here.

Before I proceed to outline the conception of an autonomous social science for Asia, I should like to be excused for using materials from my own works. Certainly there are other works by other authors but I feel safer to use my own works since I had given much personal attention to the materials used in them. For an autonomous tradition the first requirement is posing a definite problem. Around 1966, I became interested in the theme of the lazy native. The first question I posed was why were the natives of Indonesia, Malaysia and the Philippines judged as lazy, by hundreds of authors from the ruling colonial regime, in the course of some four centuries. There are probably thousands of published references on this theme. Neither the conduct of the natives, nor pressing political exigencies required the promulgation of such a judgement. A simple explanation, namely, rationalization of colonial rule was not needed in the colonies, or in the ruling countries.

Such an inquiry had not been carried out before, in the sense of a research question requiring years of effort. While researching I realized that I had to conceptualize certain phenomena because existing concepts were not suitable. Hence I evolved the concept of colonial capitalism as distinct from other forms of capitalism recognised in Western countries. Certain neglected phenomena crucial to the history of Malaysia and Indonesia, such as the destruction of the trading classes by colonial rule, had to be seriously studied and the sociological mechanism bringing abou the destruction had to be described in order to understand the motives of the aliens to describe the natives as 'lazy'.

In the course of the undertaking I had directly to experience the crossing of arbitrary boundaries laid by the disciplines sociology, history, anthropology and psychology. The end result is a book sent to, and taken by the publisher in 1973, and published in 1977 (Alatas, 1977). Although there was a great deal of critical discussion of some authors, my course was to steer away from the direction set by them. I applied my own criteria of relevance from the regional point of view. For instance, I suggested the speculative thesis, as a side issue, that Southeast Asia would have assimilated from the Western World much more intensively had there been no Western domination. This speculation was induced by historical data. To us, this is a highly relevant speculation, if we bear in mind that some speculations, as overflows of empirical historical studies, are useful, in the sense that a discussion on them would reveal further truths, as was the case with the discussion on the Pirenne thesis in Europe on what would have happened if the greater part of the Mediterranean region were not to have fallen to the Muslims in the 9th century. ${ }^{1}$

One crucial question has to be answered if we wish to see the growth of an autonomous social science tradition in Asia. Should Asian social science isolate itself from that of the West and the rest of the world? Definitely not. On the contrary, there should be greater and continuous attention paid to knowledge developed elsewhere, particularly in the West. But the problem is to select the significant from the trivial. Not everything on Asia or the West written by Western or Asian scholars is significant. The heap of trivial materials is quite big. We can here at best isolate them into three groups: (1) general scientific knowledge which is universally valid, (2) knowledge on Western societies which is of little or no interest to the developing societies, and (3) knowledge about the past and present of the West which is of high comparative value to the developing societies.

On the question of universal scientific knowledge, the difficulty in the social sciences is to isolate the universal from the particular. Let us take the concept of 'bourgeoisie.' Is the core element of the concept universally applicable? What is universal and what is particular in the German bourgeoisie? If the concept contains a universal core how do we apply it to India? Almost every concept in the social sciences has to be scrutinized in this manner.

It is easier to identify that knowledge of the Western society which is of no interest to the developing world. But the problem is with those aspects of the West that are highly relevant. An example is the fact against corruption in America.

As to knowledge on the developing societies generated in the West, there are many sound and useful reports and surveys or quantitative studies. Our concern here is mainly with analytic and interpretative studies of Asia. An example is the suggestion by the West that developing societies should pay more attention to applied research rather than to basic research. This is not acceptable as the need for a basic research is as great as applied research in the developing societies.

There is also the significant need to classify, from yet another perspective, the kind of knowledge to be developed by an autonomous social 
science tradition. It is the following: (1) Foundational knowledge, (2) consolidative knowledge (3) reactive knowledge, and (4) developmental knowledge. Foundational knowledge refers to knowledge of the foundations of Asian societies, their culture, religion and other crucial aspects of societal life. Consolidative knowledge refers to knowledge that consolidates and strengthens the foundations. Reactive knowledge refers to knowledge that is required to react to ideas that tend to strengthen or corrode the basis of social life. Developmental knowledge is knowledge required to attain peace, justice, welfare and insight into human living.

The above types of knowledge are relevant in the sense that they point to the goals of an autonomous social science tradition. It is definitely based on values but the kind of values that are the necessary guide for every kind of scientific activity. What is the goal of criminology? To prevent or to increase crime? We are not here suggesting a naive and uncritical value judgement. Without value premises science becomes a nihilistic enterprise or falls as a prey to unscrupulous manipulation. I am not suggesting the kind of value premises required but only stressing the need for such premises.

The influence of the nihilistic trend should not be minimized. ${ }^{2}$ In the social sciences, it has taken various forms one of which is to ignore the idea of significance. Topics are selected without any consideration of significance. This is most apparent in the selection of topics for post-graduate theses. The idea of significance should not be confused with the scope of research. A limitation in scope may yet involve significance if the inquiry is related to significant problems. We are, however, inundated with publications on limited topics without any significance whatsoever. What worries is the fact that these publications are considered 'scientific', because science does not insist on the idea of significance. Suppose someone was to study the physics and chemistry of the toenail. This study may be scientific but how significant is it to our understanding of the complex human body? Suppose we were to invent a machine to count the number of strands of hair on a human head. How significant will this invention be? It is apparent that the criteria of significance cannot be derived from science. They are derived from our extra-scientific orientation.

An autonomous social science tradition in Asia would have to rely on criteria of significance distinctive of the region. This reminds me of Ortega $y$ Gasset's description of a thinker's ideas consisting of, what he calls, the subsoil, the soil and the adversary. The following is his description: "The subsoil, composed of deep layers rooted in ancient collective thought from which a particular thinker derives his ideas, is generally something he is unconscious of. The soil is of recent creation - the fundamental, newly founded ideas accepted by the thinker. It is the soil in which he is grounded, and from which his own unique thought and ideas stem. Hence he does not refer to it, just as one does not indicate to people the ground upon which one's feet tread at each moment. Finally, all thought represents thought against, whether so indicated verbally or not. Our creative thought is always shaped in opposition to some other thought, which we believe erroneous, fallacious, and needful of correction. I call this the adversary, a menacing bluff, which at a particular moment looms above our soil, and hence likereise emerges from that soil, and in contrast with which the configuration of our own doctrine takes form. The adversary is never an ineffectual past: it is always contemporary and seemingly vestigial." (Gasset, 1967:73-74)

There is a combative element in the sciences. This combative element has not been sufficiently developed in the social sciences in Asia. I am here not referring to that aspect of social science research where no combat is required. But there is another kind of activity where the combative element is required. This is if we were to react to the kind of suggestions made by Toynbee, namely that the world is being Westernized. For the Asian countries this distinction is vital. ${ }^{3}$

The theme of an autonomous social science tradition should not be confused with what is called the indigenization of social science knowledge. There should not be an indigenization of the social sciences because the concept of indigenization does not apply to the sciences. What applies is the result of the scientific approach, the product of science. Let us take the example of the radio. Is it indigenous to the Philippines? We say no but it is in the process of becoming. Yes, as far as the radio is concerned. But can we indigenize the science and technology of the radio? No, we cannot and should not. The science and technology of the radio is universal, it is in a state of flux, it is a global activity, and it cannot be integrated into any particular cultural and traditional pre-existing mould.

When we indigenize we are fitting the entity into a pre-existing mould Hence it would be more accurate to speak of the autonomous development of the social sciences rather than the indigenization of the social sciences. We can adopt new cultural objects without indigenizing the object and the social sciences responsible for its creation.

A reflection on the meaning of indigenization and autonomous development should not be taken as a mere wrangling on terminology. It reveals the nature, function and genesis of the scientific spirit, the forward movement of humanity, the necessity to break with the past to forge something new but at the same time to preserve what is considered as valuable from the past. The spirit of indigenization cannot facilitate the development of the social sciences.

Indigenization belongs to a different sphere such as customs, usages, plants, animals, climate and food habits. Indigenization refers to the relative and particular while science is general and universal. It is true that science and knowledge can be expropriated by indigenization as what the Nazis did but it became no more true science and objective knowledge.

However our greater concern is not the issue of indigenization but 
the deeper and more pervasive tension between the old and the new. As a reminder let us hear the words of that great Russian thinker Alexander Herzen:

The old and the vanquished does not immediately descend into the grave. The resistance and longevity of that which is at the point of vanishing are based on the instinct that defends to the utmost everything once endowed with life. Universal economy does not allow the existing things to descend into the grave before they have exhausted all their strength. Conservation in the historical world is as true an element of life as is perpetual motion and renewal; it expresses a most emphatic approval of the existing, a recognition of its right. The urge to forward, on the contrary, expresses dissatisfaction with the existing, and seeks for a form better adapted to the new stage of the development of reason. Content with nothing, it is indignant, it feels cramped under the existing scheme of things. Historic developmen moves in obedience to both forces, balancing them against each other and thereby saving itself from one-sidedness. (Herzen, 1956 (1845):213).

To surge forward and breakaway from the existing scheme of things, it is necessary that Asian social scientists forge a new trend in the study of Asia. There should be a distinctive selection of Asian problems and a distinctive combination of disciplines and composite background knowledge. The late Ali Shariati, the Iranian sociologist and reformer, gave considerable attention to the phenomenon of martyrdom. Sociology of martyrdom can be developed in Asia. Similarly there are numerous other topics that can be introduced into world of research in Asian social science.

Several years ago, in New Delhi, during a conference, I suggested to a good friend, a leading Indian sociologist, that we start a new branch of inquiry urgently needed in Asia. In an outwardly hilarious mood but inwardly serious, over a cup of coffee at the cafeteria, I suggested to call this sub-discipline creepology that is from creeping and crawling, the abject phenomenon of flattery. I had started drawing up a classification of concepts around the core phenomenon such as creepoactive, creepogenic, creepant, creepomania, and creepophobia. The creepo syndrome can be further analyzed and classified into types, such as the feline type or the canine type. The feline type is the quiet soothing flatterer (creepant) while the canine type is the noisy, obtrusive, highly active, tail wagging, jumping and licking, and last but not least, drooling. When the creepo syndrome became pervasive amongst those in poling. When the creepo synon the well being of an illustration of the unlion this merely as an unlimited possibility of generating new themes of research on Asian societies. Side by side with generating new themes, it would be helpful to produce an Asian dictionary of the social sciences where space can be given to Asian phenomena and link them with the universal concepts of the social sciences. Similarly an Asian journal of the social sciences has to play its role.

Another significant undertaking is to continuously draw from the experience of the West and to participate in theory construction and conceptual refinement. It is a fact that Max Weber had been little discussed amongst Asian social scientists compared with those in the West. A lot of the writings around the French Revolution are meaningful for Asia. The abundant analogous phenomena such as the absence of the social conscience before, how this was developed, the fight against religious intolerance, the humanization of laws and government and the implantation of human rights were connected to the manner of attaining them. This is valuable for Asia. Hence making that aspect of Western history known to Asian society will affect the direction of social change in Asia.

In the context of this paper, the focus and urgency has centred on practical demonstration and illustration of specific problems, rather than a comprehensive and total account of the numerous and complex discussion regarding the development of an autonomous social science tradition in Asia.

\section{Notes}

1. On this see Pirenne (1954). Mohammed and Charlemagne. London: Tr. B. Miall. Allen and Unwin.

2. On the relation between nihilism and European culture, see Goudsblom (1977) Nihilisme en Cultuur. Amsterdam: Athenaeum, Polak, van Gennep.

3. See Toynbee (1962:24). Present Day Experiment in Western Civilization. Oxford University Press, London. For a refutation of Toynbee's view see Alatas (1972), Modernization and Social Change. Sydney: Angus and Robertson.

\section{References}

Alatas, S.H. (1977) The Myth of the Lazy Native. London: Frank Cass.

Gasset, Jose Ortega Y. (1967) The Origin of Philosophy. New York: Tr.T Talbot, W.W. Norton.

Goudsblom, J. (1977) Nihilisme en Culturur. Athenaeum. Amsterdam: Polak, van Gennep. Herzen, Alexander (1956) "Letters on the Study of Nature (1845)". Selected Philosophical Works. Moscow: Foreign Languages Publishing House.

Pirenne, H. (1954) Mohammed and Charlemagne. Tr.B.Miall., London: Allen and Unwin Toynbee, A.J. (1962) Present Day Experiment in Western Cwilization. London: Oxford University Press. 